\title{
Enhanced Oil Removal by a Non-Toxic Biosurfactant Formulation
}

\author{
Emília Mendes da Silva Santos 1,2, Isabela Regina Alvares da Silva Lira ${ }^{1,2}$, Hugo Moraes Meira 1,2, \\ Jaciana dos Santos Aguiar ${ }^{3}$, Raquel Diniz Rufino ${ }^{2,4}$, Darne Germano de Almeida ${ }^{1}$, \\ Alessandro Alberto Casazza ${ }^{5}(0)$, Attilio Converti ${ }^{5, *(-)}$, Leonie Asfora Sarubbo ${ }^{1,2}\left(\mathbb{D}\right.$ and Juliana Moura de Luna ${ }^{1,2}$
}

\section{check for}

updates

Citation: Mendes da Silva Santos, E. Alvares da Silva Lira, I.R.; Moraes

Meira, H.; dos Santos Aguiar, J.; Diniz

Rufino, R.; Germano de Almeida, D.;

Casazza, A.A.; Converti, A.; Asfora

Sarubbo, L.; Moura de Luna, J.

Enhanced Oil Removal by a

Non-Toxic Biosurfactant Formulation.

Energies 2021, 14, 467. https://doi.

org/10.3390/en14020467

Received: 21 November 2020

Accepted: 13 January 2021

Published: 17 January 2021

Publisher's Note: MDPI stays neutral with regard to jurisdictional clai$\mathrm{ms}$ in published maps and institutional affiliations.

Copyright: (C) 2021 by the authors. Licensee MDPI, Basel, Switzerland. This article is an open access article distributed under the terms and conditions of the Creative Commons Attribution (CC BY) license (https:// creativecommons.org/licenses/by/ $4.0 /)$.
1 Biotechnology Sector, Catholic University of Pernambuco (UNICAP), Rua do Príncipe, n. 526, Boa Vista, Recife 50050-900, Brazil; emiliamendes.farma@gmail.com (E.M.d.S.S.); enf.isabelalira@hotmail.com (I.R.A.d.S.L.); hugo_morais15@hotmail.com (H.M.M.); darnebio@yahoo.com.br (D.G.d.A.); leonie.sarubbo@unicap.br (L.A.S.); Juliana.luna@unicap.br (J.M.d.L.)

2 Advanced Institute of Technology and Innovation (IATI), Rua Joaquim de Brito, 216, Boa Vista, Recife 50070-280, Brazil; raqueldrufino@yahoo.com.br

3 Center of Biological Sciences, Department of Antibiotics, Federal University of Pernambuco, Av. Prof. Artur de Sá, s/n, Cidade Universitária, CEP, Recife 54740-520, Brazil; jacianaaguiar@gmail.com

4 School of Integration of the Semiarid (FIS), Rua João Luiz de Melo, 2110, Tancredo Neves, Serra Talhada 56909-205, Brazil

5 Department of Civil, Chemical and Environmental Engineering, Pole of Chemical Engineering, Università degli Studi di Genova (UNIGE), Via Opera Pia 15, I-16145 Genova, Italy; alessandro.casazza@unige.it

* Correspondence: converti@unige.it; Tel.: +39-010-3352593

Abstract: In this study, a new formulation of low-cost, biodegradable, and non-toxic biosurfactant by Candida sphaerica UCP 0995 was investigated. The study was conducted in a bioreactor on an industrial waste-based medium, and a central composite rotatable design was used for optimization. The best results, namely a $25.22 \mathrm{mN} / \mathrm{m}$ reduction in surface tension, a biosurfactant yield of $10.0 \mathrm{~g} / \mathrm{L}$, and a critical micelle concentration of $0.2 \mathrm{~g} / \mathrm{L}$, were achieved in $132 \mathrm{~h}$ at an agitation speed of $175 \mathrm{rpm}$ and an aeration rate of $1.5 \mathrm{vvm}$. Compositional and spectroscopic analyses of the purified biosurfactant by chemical methods, Fourier transform infrared spectroscopy, and nuclear magnetic resonance suggested that it is a glycolipid-type biosurfactant, and it showed no cytotoxicity in the MTT assay. The biosurfactant, submitted to different formulation methods as a commercial additive, remained stable for 120 days at room temperature. Tensioactive properties and stability were evaluated at different $\mathrm{pH}$ values, temperatures, and salt concentrations. The biosurfactant obtained with all formulation methods demonstrated good stability, with tolerance to wide ranges of $\mathrm{pH}$, temperature and salinity, enabling application under extreme environmental conditions. Bioremediation tests were performed to check the efficacy of the isolated biosurfactant and the selected microbial species in removing oil from soil. The results demonstrated that the biosurfactant produced has promising properties as an agent for the bioremediation of contaminated soil.

Keywords: biosurfactant; industrial waste; petroleum contamination; Candida

\section{Introduction}

With the technological advances of the past few decades, refineries have significantly increased the production of petroleum and petroleum by-products. A major drawback of this increase is the occurrence of oil spills during the extraction, transport, and transference of oil between ships, which cause environmental pollution and other environmental risks, with a considerable impact on society [1-3].

Petroleum-based compounds are highly polluting when released into the environment, posing considerable public health and environmental problems, due to soil and water contamination $[1,4]$. The need to remediate contaminated areas has led to the development 
of new technologies, such as bioremediation that involves the use of microorganisms and/or their metabolites for the degradation of pollutants [5]. Although techniques based on chemical, electrochemical, and thermal strategies are effective for the ex-situ treatment of contaminated sediments and soils, bioremediation methods are promising due to their low-cost technology and lower environmental impact [6].

Biosurfactants are synthesized by bacteria, yeasts, and filamentous fungi by fermentation, and can be also extracted from plants. Surfactant compounds are in fact found in different parts of plants, such as the roots, stems, seeds, fruit, and leaves [7]. Based on the charge carried by their polar groups, surfactants are classified as cationic, anionic, amphoteric, or non-ionic. Biosurfactants have attracted considerable attention as alternatives to their synthetic counterparts, offering the advantages of lower toxicity, and potentially high activity and stability at extreme values of temperature, $\mathrm{pH}$, and salinity. Most importantly, these substances are biodegradable, making them environmentally friendly, "green" chemicals [8].

However, despite their advantages, biosurfactants are not yet competitive because of their high production costs, and most commercially available ones are still prepared from petroleum. In fact, petroleum-based surfactants currently account for 70 to $75 \%$ of all surfactants used in industrialized countries [9]. Therefore, the development of low-cost processes for biosurfactant production is crucial to reduce costs and increase competitiveness. In this context, industrial waste products have sparked the interest of researchers as low-cost substrates for producing biosurfactants, since the substrate cost can represent up to $50 \%$ of the final production cost [4].

The so-called response surface methodology and contour plots are statistical tools often used to optimize the growth medium and culture conditions, with the aim of maximizing yield [10]. The use of bioreactors has also become an attractive option, in combination with culture conditions previously optimized in shaken flasks, to reduce the cost and duration of the process. Thus, the large-scale production of biosurfactants is an effective strategy for competing with their synthetic counterparts [4].

Numerous studies have described the combined use of a sugar and an insoluble substrate as components of the broth for achieving a high biosurfactant yield [11,12]. However, as with all industrially important metabolites, the maximization of biosurfactant production through fermentation processes requires the standardization of the medium and culture conditions [10]. In this regard, statistical modeling is an important tool for determining the effects of components and conditions, as well as the interaction of these variables on the performance of a given process [13].

It is paramount to develop strategies that enable producing and subsequently applying biosurfactants on an industrial scale. To this end, low-cost substrates, selection of producing microorganisms, and improvement of purification processes have been used [14].

Therefore, the aim of this study was to maximize the production of a biosurfactant by the yeast Candida sphaerica UCP 0995, cultured in a cheap medium in a bioreactor, using a central composite rotatable design (CCRD). We also described the properties of the biosurfactant, its isolation, characterization, commercial formulation, and application in the removal of a petroleum-based oil from terrestrial and marine environments.

\section{Materials and Methods}

\subsection{Materials}

All chemicals were reagent grade and purchased from Sigma-Aldrich (St. Louis, MO, USA), while culture media were acquired from Difco Laboratories (Detroit, MI, USA). For biosurfactant production, two industrial waste products, namely groundnut oil refinery residue supplied by ASA Ltda (Recife, Brazil), and corn steep liquor supplied by Corn Products do Brazil (Cabo de Santo Agostinho, Brazil), were used as carbon and nitrogen sources, respectively. Both by-products also provided other essential nutrients for yeast metabolism. The former waste was composed of $(w / w) 60 \%$ fats, 35\% carbohydrates, $2.7 \%$ sodium, $0.08 \%$ magnesium, $0.063 \%$ potassium, and $0.004 \%$ zinc, while the latter of $(w / w)$ 
21 to $45 \%$ proteins, 20 to $26 \%$ lactic acid, $8 \%$ ash (containing $\mathrm{Ca}^{2+}, \mathrm{Mg}^{2+}$ and $\mathrm{K}^{+}$), $3 \%$ sugars, and only 0.9 to $1.2 \%$ fats.

\subsection{Microorganism}

Candida sphaerica UCP 0995 deposited in the Culture Bank of the Center for Environmental Sciences and Biotechnology of the Catholic University of Pernambuco (Recife, Brazil) was tested as the biosurfactant producer. Cultures of the strain were kept at $5{ }^{\circ} \mathrm{C}$ in slants containing yeast mold agar (YMA) and sub-cultured every 30 days.

\subsection{Culture Conditions and Biomass Concentration}

The yeast inoculum was prepared by transferring the culture to a tube containing YMA to obtain a young culture. Next, the sample was transferred to flasks containing $50 \mathrm{~mL}$ of yeast mold broth (YMB) (yeast extract $0.3 \%$, malt extract $0.3 \%$, tryptone $0.5 \%$, and D-glucose $1.0 \% \mathrm{w} / \mathrm{v}$ ) and incubated under stirring at $150 \mathrm{rpm}$ for $24 \mathrm{~h}$ at $28^{\circ} \mathrm{C}$. The inoculum $(1 \% v / v)$ was added to the medium up to a concentration of $10^{4}$ cells $/ \mathrm{mL}$. The medium for biosurfactant production was composed of distilled water supplemented with 9\% groundnut oil refinery residue and 9\% corn steep liquor, and sterilized in an autoclave at $121{ }^{\circ} \mathrm{C}$ for $20 \mathrm{~min}$. To produce the biosurfactant, fermentations were carried out in a 4.0-L bioreactor (TEC-BIO FLEX II, Tecnal, Piracicaba, Brazil) following the experimental planning described below. At the end of the cultures, samples were taken, centrifuged, and filtered to determine the surface tension and biosurfactant yield.

To determine dry biomass concentration, 10-mL aliquots of the fermented broth were centrifuged at $2000 \times g$ for $20 \mathrm{~min}$, and biomass was washed in distilled water in a graduated centrifuge tube. After agitation and further centrifugation, the upper phase was discarded. The cell pellet was dried in a forced-air oven at $105^{\circ} \mathrm{C}$ for $24 \mathrm{~h}$ and weighed [15].

\subsection{Optimization of Biosurfactant Production}

A central composite rotatable design (CCRD) was used to investigate the effects and possible interactions of three factors (agitation speed, aeration rate, and culture time) on biosurfactant production. Surface tension of the production medium containing the biosurfactant was selected as the response variable and used as the selection criterion for optimal production conditions.

Twenty experiments were performed with four repetitions of the central point. The statistical analysis of results was used to give an indication of the experimental error of the production method. Table 1 lists the range and levels of the independent variables. Each variable was studied on five levels $(-1.68,-1.0,0,+1$, and +1.68$)$, with zero as the coded central value, which were selected based on the results of preliminary experiments [16].

Table 1. Experimental ranges and coded levels of the independent variables used in the central composite rotational design to optimize biosurfactant production by Candida sphaerica (UCP 0995).

\begin{tabular}{cccccc}
\hline Variables & \multicolumn{5}{c}{ Ranges and Coded Levels } \\
\cline { 2 - 6 } & $-\mathbf{1 . 6 8}$ & $\mathbf{- 1}$ & $\mathbf{0}$ & $\mathbf{+ 1}$ & $\mathbf{+ 1 . 6 8}$ \\
\hline Agitation speed (rpm), $x_{1}$ & 125 & 150 & 200 & 250 & 275 \\
Aeration rate (vvm), $x_{2}$ & 0.0 & 0.5 & 1.0 & 1.5 & 2.0 \\
Culture time (h), $x_{3}$ & 96 & 108 & 120 & 132 & 144 \\
\hline
\end{tabular}

Optimal conditions of the CCRD were identified by solving the quadratic polynomial equation describing the linear, quadratic, and interaction effects of variables on surface tension and analyzing the response surface plots. Analysis of variance (ANOVA) with a $95 \%$ confidence interval was used to determine the significance of the effects. The Statistica ${ }^{\circledR}$ version 10.0 software (Statsoft, Tulsa, OK, USA) was used for ANOVA, determination of regression coefficients, and creation of graphs. 


\subsection{Surface Tension and Critical Micelle Concentration Determinations}

Surface tension (ST) changes were measured on the cell-free broth obtained by centrifuging the cultures at $5000 \times g$ for $20 \mathrm{~min}$ by the ring method, using a Sigma 700 Tensiometer (KSV Instruments Ltd., Helsinki, Finland) at room temperature.

The critical micelle concentration (CMC) was determined with the same equipment by measuring the ST of solutions of the isolated biosurfactant in distilled water until the achievement of a constant ST value. Stabilization was considered achieved when the standard deviation from the mean of ten subsequent ST measurements was below $0.4 \mathrm{mN} / \mathrm{m}$. The value of CMC was calculated from the plot of ST versus biosurfactant concentration [16].

\subsection{Isolation of Biosurfactant}

The biosurfactant was extracted from the fermented broth after removal of cells by centrifugation $\left(5000 \times g, 15 \mathrm{~min}, 4^{\circ} \mathrm{C}\right)$ and vacuum filtration. The same volume of ethyl acetate $(1: 1, v / v)$ was added to the cell-free broth. The mixture was vigorously stirred for $15 \mathrm{~min}$ and allowed to stand to separate the phases. The samples were extracted twice. The organic phase was evaporated at $40{ }^{\circ} \mathrm{C}$ to remove the solvent. The residue obtained was washed twice with hexane to remove any remaining hydrophobic substance, such as fatty acids and alcohols resulting from fermentation. After extraction, the product was treated with a base and crystallized for maximum removal of impurities [17].

\subsection{Fourier-Transform Infrared Spectroscopy}

The surfactant-containing extract recovered from the supernatant was characterized using a Fourier-transform infrared (FTIR) spectroscope (Spectrum 400, Perkin Elmer, Shelton, CT, USA), with $4 \mathrm{~cm}^{-1}$ resolution in the region $400-4000 \mathrm{~cm}^{-1}$.

\subsection{Nuclear Magnetic Resonance Spectroscopy}

The extracted biosurfactant was redissolved in deuterated chloroform, and the respective ${ }^{1} \mathrm{H}$ NMR and $\mathrm{C}$ NMR spectra were recorded at $25^{\circ} \mathrm{C}$ using a $300 \mathrm{MHz}$ spectrometer (Agilent, Santa Clara, CA, USA) operating at $300.13 \mathrm{MHz}$. Chemical displacements ( $\delta$ ) were expressed in ppm in relation to tetramethylsilane.

\subsection{Gas Chromatography}

The fatty acids (hydrophobic fraction) of the biosurfactant were analyzed with a gas chromatograph (GC), model HP 5890 Series II (Hewlett Packard, Palo Alto, Santa Clara, CA, USA) at an injector temperature of $220^{\circ} \mathrm{C}$. Chromatographic separation was performed in a DB-5 column $(30 \mathrm{~m} \times 0.32 \mathrm{~mm} \times 0.5 \mu \mathrm{m})$ with a flame ionization detector (FID) at $290^{\circ} \mathrm{C}$ using nitrogen as the carrier gas. The initial temperature was raised from $60^{\circ} \mathrm{C}$, at a rate of $7{ }^{\circ} \mathrm{C} / \mathrm{min}$, until the final temperature of $200{ }^{\circ} \mathrm{C}$ was reached. One $\mu \mathrm{L}$ of sample was injected using hexane as the solvent.

\subsection{Formulation of Biosurfactant}

The surfactant-containing cell-free medium was stored using the following procedure: (1) the broth was supplemented with $0.2 \%$ potassium sorbate as a preservative; (2) the broth was heated to $80^{\circ} \mathrm{C}$ (fluent steam) for $30 \mathrm{~min}$, followed by $0.2 \%$ potassium sorbate addition; then (3) the broth was sterilized by fractionated tyndallization (fluent steam) for $30 \mathrm{~min}$, for 3 days. Tests were performed on the treated broth to determine its stability after different storage times $(0,15,30,45,90$, and 120 days $)$ at room temperature $\left(28^{\circ} \mathrm{C}\right)$. Stability was determined based on ST, emulsification activity, and motor oil dispersion in seawater [18].

\subsection{Determination of Emulsifying Activity}

The emulsifying activity of the formulated surfactant contained in the cell-free broth was determined using the method described by Cooper and Goldenberg [19]. One milliliter of motor oil obtained from a local automotive manufacturer in Recife (Brazil) was added 
to $1.0 \mathrm{~mL}$ of the broth in a graduated tube, and the mixture was vortexed for $2 \mathrm{~min}$. The emulsion stability was determined after $24 \mathrm{~h}$, and the emulsification index was calculated as a percentage, by dividing the measured height of the emulsion layer by the total height of the mixture and multiplying by 100 .

\subsection{Hydrophobic Compound Dispersion Test in Water}

This assay was done by adding $40 \mathrm{~mL}$ of water to a Petri dish with a diameter of $15 \mathrm{~cm}$. A $1.0 \%$ solution of the formulated biosurfactant was added up to a biosurfactant-to-oil proportion of $1: 2(v / v)$. The effect of different temperatures $\left(40\right.$ and $\left.50{ }^{\circ} \mathrm{C}\right), \mathrm{NaCl}$ concentrations $(1.0,3.0$ and $5.0 \% w / v)$, and $\mathrm{pH}$ values (5.0 and 7.0) on the surfactant dispersion power was investigated. The results from triplicate experiments were expressed as the mean diameter of clear zones that appeared in Petri dishes, and the dispersion index was defined as the percentage of the mean diameter with respect to the dish diameter $(15 \mathrm{~cm})$ [17].

\subsection{Effect of Environmental Factors on the Activity of Formulated Biosurfactant}

The effects of different temperatures $\left(40\right.$ and $\left.50{ }^{\circ} \mathrm{C}\right)$, concentrations of $\mathrm{NaCl}(1.0$, 3.0 and 5.0\%), and $\mathrm{pH}$ values (5.0, 7.0 and 9.0) on the emulsification and surface-active properties of the formulated biosurfactant were evaluated in the cell-free broth after 0,15 , $30,45,90$, and 120 days. All analyses were done in triplicate [18].

\subsection{Evaluation of Biosurfactant Cytotoxicity}

Cytotoxicity of the biosurfactant was assessed by the colorimetric methylthiazolyldiphenyltetrazolium bromide (MTT) method. The L929 (mouse fibroblast) cell line was maintained in Dulbecco's modified Eagle's medium, while the HCT116 (human colorectal carcinoma) cell line was maintained in Roswell Park Memorial Institute (RPMI 1640) medium. All media were supplemented with $10 \%$ fetal bovine serum and a $1 \%$ penicillin/streptomycin solution. Cells were kept at $37{ }^{\circ} \mathrm{C}$ in a humid atmosphere enriched with $5 \% \mathrm{CO}_{2}[20,21]$.

Cell suspensions with $2 \times 10^{5}$ cells $/ \mathrm{mL}$ cell density were plated in 96-well plates and incubated for $24 \mathrm{~h}$. Next, $100 \mu \mathrm{L}$ of the biosurfactant solutions were added to the wells at concentrations of 0.094 to $12 \mathrm{mg} / \mathrm{mL}$. After $72 \mathrm{~h}, 25 \mu \mathrm{L}$ of $5 \mathrm{mg} / \mathrm{mL}$ MTT were added, followed by incubation for $3 \mathrm{~h}$. Culture media with MTT were aspirated, and $100 \mu \mathrm{L}$ of dimethyl sulfoxide were added to each well. Absorbance was read in a microplate reader (DR-200BN-BI, Kasuaki, Campinas, Brazil) at a wavelength of $560 \mathrm{~nm}$. The experiments were performed in triplicate to determine the mean cell viability. Differences in mean cell viability were evaluated by one-way ANOVA and Tukey's post hoc test $(p<0.05)$, with the aid of the GraphPad Prism 7.0 demo software (GraphPad Software Inc., La Jolla, CA, USA).

\subsection{Bioremediation of Petroleum Product Adsorbed on Sand}

Samples $(10 \mathrm{~g})$ of sand contaminated with motor oil were added to $100 \mathrm{~mL}$ of running water, and the mixture was supplemented with $1 \mathrm{~mL}$ of sugarcane molasses as a carbon source, which was acquired from a local sugar plant. The mixture was sterilized with fluent steam, which constituted a control condition. Next, solutions of the isolated biosurfactant at $\frac{1}{2} \mathrm{CMC}, \mathrm{CMC}$, and $2 \times \mathrm{CMC}$, and $15 \%$ of the yeast inoculum suspension, containing $10^{8}$ cells $/ \mathrm{mL}$ previously cultured in $\mathrm{YMB}$, were added. The mixtures were incubated at $150 \mathrm{rpm}$ for 90 days at $28^{\circ} \mathrm{C}$.

One percent molasses was added to the mixtures every 15 days in each 90-day experiment. Samples (5 mL) were taken every 15 days $(15,30,45,60,75$, and 90 days) to determine the percentage of motor oil removed from the sand, totaling seven samples. The percentage of degraded oil was calculated from the amount of oil removed, which was determined by gravimetry [22].

\subsection{Static Assay}

Glass columns $(55 \times 6 \mathrm{~cm})$ were filled with approximately $200 \mathrm{~g}$ of sand contaminated with a $10 \%(v / w)$ solution of the hydrophobic contaminant. The surface was then flooded 
with $200 \mathrm{~mL}$ of a biosurfactant solution at a concentration corresponding to $\frac{1}{2} \mathrm{CMC}, \mathrm{CMC}$, or $2 \times \mathrm{CMC}$, or with a synthetic surfactant solution. The same volume of cell-free broth containing crude biosurfactant was also tested, while a column containing soil in $200 \mathrm{~mL}$ of water (without surfactant) was used as a control. Percolation of solutions was monitored for $24 \mathrm{~h}$. Samples were withdrawn to assess oil removal gravimetrically. The residual motor oil was extracted in a pre-weighed beaker using $n$-hexane in a decanting funnel. The extraction was repeated twice to ensure complete recovery. After extraction, hexane was evaporated in a rotary evaporator, and the oil removed from the sand was weighed [23].

\subsection{Analysis of Petroleum Product Removed from Sand}

The initial amount of oil and that of oil contained in the sand were determined gravimetrically after washing the sand containing the remaining contaminant with $n$ hexane. After extraction, hexane was placed in an oven at a temperature between 68 and $70{ }^{\circ} \mathrm{C}$. The percentage of degradation $(D)$ was calculated according to the equation [24]:

$$
D(\%)=\frac{m_{\mathrm{D}}}{m_{\mathrm{A}}} \times 100
$$

where $m_{\mathrm{D}}$ and $m_{\mathrm{A}}$ are the masses of degraded oil and of oil added to the medium, respectively.

\section{Results and Discussion}

\subsection{Optimization of Biosurfactant Production Using the Central Composite Rotatable Design}

Table 2 shows the central composite rotatable design (CCRD) matrix and the experimental results of surface tension and biosurfactant yield under different conditions tested to optimize biosurfactant production by Candida sphaerica. As can be observed, run seven provided the best conditions for biosurfactant production, having ensured the lowest surface tension and, at the same time, the highest biosurfactant yield.

Table 2. Central composite rotatable design matrix used to optimize biosurfactant production by Candida sphaerica (UCP 0995), and experimental results of surface tension (response) and biosurfactant yield.

\begin{tabular}{|c|c|c|c|c|c|}
\hline Run & $\begin{array}{l}\text { Agitation Speed } \\
(\mathrm{rpm}), x_{1}\end{array}$ & $\begin{array}{l}\text { Aeration Rate } \\
(\mathrm{vvm}), x_{2}\end{array}$ & $\begin{array}{l}\text { Culture Time } \\
\text { (h), } x_{3}\end{array}$ & $\begin{array}{l}\text { Surface Tension } \\
\quad(\mathrm{mN} / \mathrm{m}), Y\end{array}$ & $\begin{array}{c}\text { Biosurfactant Yield } \\
(\mathrm{g} / \mathrm{L})\end{array}$ \\
\hline 1 & -1.0 & -1.0 & -1.0 & 28.21 & 4.5 \\
\hline 2 & +1.0 & -1.0 & -1.0 & 27.21 & 5.0 \\
\hline 3 & -1.0 & +1.0 & -1.0 & 27.80 & 2.0 \\
\hline 4 & +1.0 & +1.0 & -1.0 & 28.32 & 3.2 \\
\hline 5 & -1.0 & -1.0 & +1.0 & 26.23 & 4.0 \\
\hline 6 & +1.0 & -1.0 & +1.0 & 26.54 & 3.2 \\
\hline 7 & -1.0 & +1.0 & +1.0 & 25.22 & 10.0 \\
\hline 8 & +1.0 & +1.0 & +1.0 & 27.13 & 5.0 \\
\hline 9 & -1.68 & 0.0 & 0.0 & 30.87 & 2.2 \\
\hline 10 & +1.68 & 0.0 & 0.0 & 28.00 & 3.3 \\
\hline 11 & 0.0 & -1.68 & 0.0 & 25.68 & 6.8 \\
\hline 12 & 0.0 & +1.68 & 0.0 & 26.52 & 3.1 \\
\hline 13 & 0.0 & 0.0 & -1.68 & 26.12 & 3.1 \\
\hline 14 & 0.0 & 0.0 & +1.68 & 27.15 & 4.6 \\
\hline 15 & 0.0 & 0.0 & 0.0 & 32.18 & 5.2 \\
\hline 16 & 0.0 & 0.0 & 0.0 & 32.15 & 5.5 \\
\hline 17 & 0.0 & 0.0 & 0.0 & 32.17 & 5.3 \\
\hline 18 & 0.0 & 0.0 & 0.0 & 32.00 & 5.3 \\
\hline 19 & 0.0 & 0.0 & 0.0 & 32.32 & 5.3 \\
\hline 20 & 0.0 & 0.0 & 0.0 & 32.25 & 5.5 \\
\hline
\end{tabular}

The coefficient of variation (CV\%) was calculated for both groups of data listed in Table 2 (surface tension and biosurfactant yield) to determine the degree of dispersion and select the better response to submit to regression analysis. The very low $\mathrm{CV} \%$ found for 
the experimental data of surface tension $(9.10 \%)$ indicated a high degree of precision and adequate reliability. On the other hand, the $\mathrm{CV} \%$ was as high as $34.53 \%$ for biosurfactant yield, which indicated a higher dispersion and greater heterogeneity in the data. Thus, surface tension appeared to be more appropriate than biosurfactant yield to develop a statistical model intended to optimize the fermentation process.

Multiple regression analysis using the response surface methodology (RSM) was then performed to fit the response function to the experimental data, and to investigate the simultaneous influence of the three variables of interest, namely the agitation speed, aeration rate, and culture time. The following empirical quadratic polynomial equation was shown to best fit the experimental data of surface tension $(\mathrm{mN} / \mathrm{m})$ selected as the response variable $(Y)$ :

$$
\begin{gathered}
Y=32.1789-0.8235 x_{1}+0.1239 x_{2}+0.2542 x_{3}-0.9735 x_{1}^{2}-2.1526 x_{2}^{2}-1.9635 x_{3}^{2}-0.1400 x_{1} \times x_{2}+0.3375 x_{1} \times \\
x_{3}+0.3900 x_{2} \times x_{3}
\end{gathered}
$$

in which $x_{1}, x_{2}$, and $x_{3}$ are the coded values of agitation speed, aeration rate, and culture time, respectively.

ANOVA was then performed to validate the quadratic model, and the results are gathered in Table 3. All the linear and quadratic terms and their interactions were statistically significant $(p<0.05)$, and the $F$-value (with a 95\% confidence interval) was much higher than 4 for each variable and the respective interactions. The low pure error $(0.0579)$ indicates the excellent reproducibility of the experimental data. Moreover, the correlation coefficient $\left(\mathrm{R}^{2}=0.9981\right)$ indicates that less than $1 \%$ of the total variation cannot be explained by the empirical model.

Table 3. Results of the analysis of variance applied to the quadratic polynomial model describing the influence of independent variables on the surface tension.

\begin{tabular}{cccccc}
\hline Factor & Sum of Squares & Degrees of Freedom & Mean Square & F-Value & $p$-Value ${ }^{\text {a }}$ \\
\hline$x_{1}(\mathrm{~L})^{\mathrm{b}}$ & 9.2620 & 1 & 9.26196 & 800.054 & 0.000001 \\
$x_{1}{ }^{2}(\mathrm{Q}) \mathrm{c}$ & 13.6579 & 1 & 13.65790 & 1179.779 & 0.000000 \\
$x_{2}(\mathrm{~L})$ & 0.2098 & 1 & 0.20980 & 18.1229 & 0.008037 \\
$x_{2}^{2}(\mathrm{Q})$ & 66.7781 & 1 & 66.77808 & 5768.33 & 0.000000 \\
$x_{3}(\mathrm{~L})$ & 0.8828 & 1 & 0.88281 & 76.2582 & 0.000326 \\
$x_{3}{ }^{\mathrm{Q}}(\mathrm{Q})$ & 55.5580 & 1 & 55.55804 & 4799.14 & 0.000000 \\
$x_{1}(\mathrm{~L}) \times x_{2}(\mathrm{~L})$ & 0.1568 & 1 & 0.15680 & 13.5445 & 0.014289 \\
$x_{1}(\mathrm{~L}) \times x_{3}(\mathrm{~L})$ & 0.9112 & 1 & 0.91125 & 78.7143 & 0.000303 \\
$x_{2}(\mathrm{~L}) \times x_{3}(\mathrm{~L})$ & 1.2168 & 1 & 1.21680 & 105.107 & 0.000152 \\
Lack of Fit & 0.1891 & 5 & 0.03783 & 3.26767 & 0.109844 \\
Pure Error & 0.0579 & 5 & 0.01158 & - & - \\
Total square sum & 129.5375 & 19 & - & - & - \\
\hline
\end{tabular}

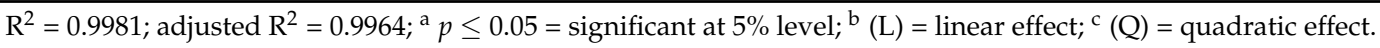

Based on the CCRD results, run seven (agitation speed: $150 \mathrm{rpm}$; aeration rate: $1.5 \mathrm{vvm;}$ culture time: $132 \mathrm{~h}$ ) was selected for biosurfactant production. The biosurfactant reduced the surface tension of the culture medium from $56 \mathrm{mN} / \mathrm{m}$ to $25.22 \mathrm{mN} / \mathrm{m}$, and a biosurfactant yield of $10.0 \mathrm{~g} / \mathrm{L}$ was reached under these conditions, although the other runs showed favorable results too.

These promising results are close to or even better than those reported in previous studies. For instance, Almeida et al. [4] reported the production of $3.0 \mathrm{~g} / \mathrm{L}$ of a biosurfactant by Candida tropicalis cultivated in a medium containing $2.5 \%$ molasses and $2.5 \%$ waste canola oil, which resulted in a surface tension of $29.52 \mathrm{mN} / \mathrm{m}$, while Luna et al. [16] reported, for the same $C$. sphaerica strain used in this work, a $8.5 \mathrm{~g} / \mathrm{L}$ biosurfactant yield in a medium containing industrial waste products and the achievement of a surface tension of $25 \mathrm{mN} / \mathrm{m}$. 


\subsection{Determination of Critical Micelle Concentration}

$\mathrm{CMC}$ is the minimum concentration of a biosurfactant required for maximum reduction of water surface tension and onset of micelle formation, which is used as a measure of the efficiency of a biosurfactant. The presence of the biosurfactant actually reduced the surface tension to an extent proportional to its concentration in solutions, until reaching CMC. Surface tension was plotted as a function of biosurfactant concentration (Figure 1). The surface tension of water in fact gradually decreased from 70 to $25.22 \mathrm{mN} / \mathrm{m}$ with increasing biosurfactant concentration up to $0.2 \mathrm{~g} / \mathrm{L}$, and then remained constant, similarly to previous observations [16].

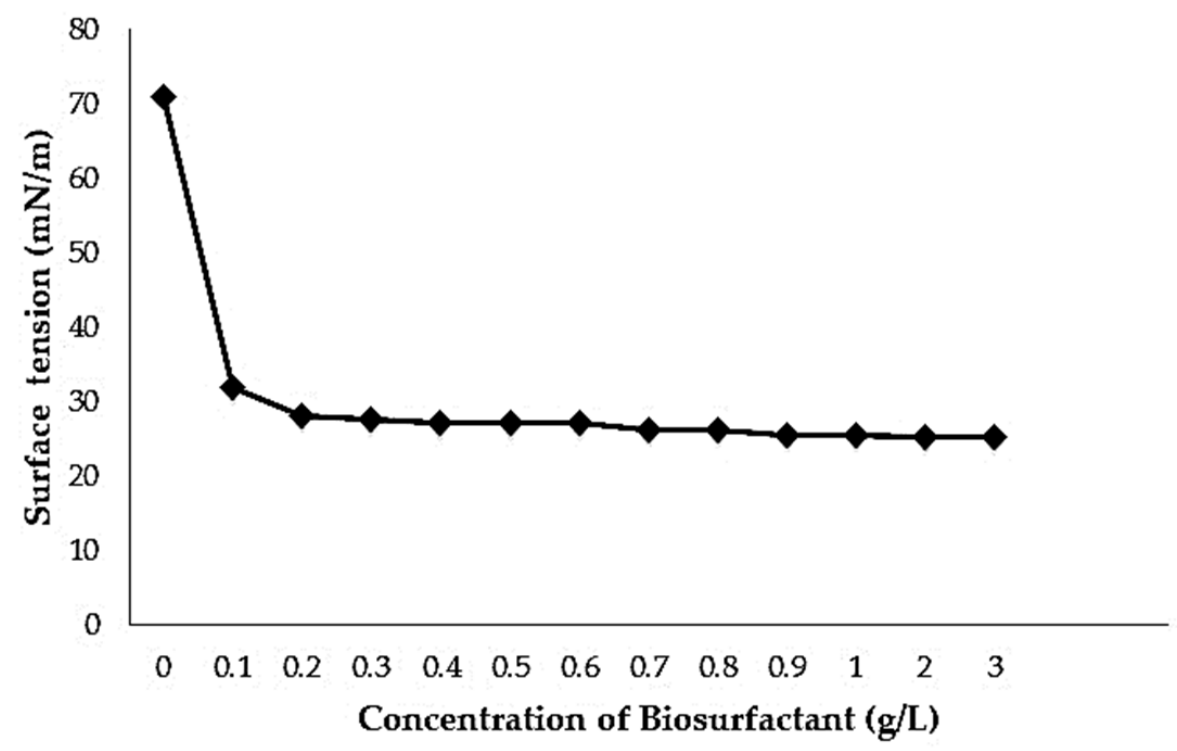

Figure 1. Critical micelle concentration of the biosurfactant produced by Candida sphaerica cultivated in medium supplemented with $9 \%$ vegetable oil refinery residue and $9 \%$ corn steep liquor.

\subsection{Structural Characterization of Biosurfactant}

The biochemical composition of microbial biosurfactants, which are classified as lipids, glycolipids, lipopeptides, and polysaccharide-protein complexes, depends on the genome of the microorganism, as well as the substrate used in the production medium [23].

Figure 2 shows the FTIR spectrum obtained for the isolated biosurfactant produced by $C$. sphaerica. The infrared spectrum exhibited absorbance bands in the wavenumber range between 3000 and $3500 \mathrm{~cm}^{-1}$, highlighting the presence of hydroxyl groups. A peak corresponding to the carbonyl functional group $(\mathrm{C}=\mathrm{O})$ was found at $1710.96 \mathrm{~cm}^{-1}$, while the presence of aliphatic carbons was evidenced by the bands at 2924.41 and $2854.02 \mathrm{~cm}^{-1}$. Moreover, the $1464.69 \mathrm{~cm}^{-1}$ band suggested the occurrence of $\mathrm{C}=\mathrm{C}$ double bonds.

The signal in the ${ }^{1} \mathrm{H}$ NMR spectrum (Figure 3) between $\delta 10$ and $11 \mathrm{ppm}$ is very characteristic of hydrogen bonded to hydroxyl close to carbonyl, indicating the presence of a carboxylic acid in the molecule. Moreover, those in the ranges $\delta 5-6$ ppm and 1-3 ppm suggested the presence of double bonds and aliphatic groups, respectively.

The ${ }^{13} \mathrm{C}$ NMR spectrum (Figure 4) revealed three well-defined regions. The signal at $\delta 180 \mathrm{ppm}$ suggested carbon bonded to the carboxyl group, the signals between $\delta 120$ and $140 \mathrm{ppm}$ confirmed the presence of $\mathrm{C}=\mathrm{C}$ double bonds, and those between $\delta 10$ and $40 \mathrm{ppm}$ corresponded to aliphatic carbons. On the other hand, the peak at $\cong \delta 80 \mathrm{ppm}$ was attributed to the residual signal of the solvent $\left(\mathrm{CDCl}_{3}\right)$.

The biosurfactant produced by $C$. sphaerica was also analyzed using GC and compared to data from the library. As illustrated in Figure 5, the main peaks were obtained at retention times of $17.55,20.82,24.62,25.03,25.72$, and $26.78 \mathrm{~min}$, which indicates that the biosurfactant was composed mainly of long-chain fatty acids. In particular, the predominant peak found at $20.82 \mathrm{~min}$, which corresponded to $46.52 \%$ of the substance with the highest concentration, 
represented C-18 fatty acids, with the most representative structure having a mass-to-charge ratio between 150 and $200(\mathrm{~m} / \mathrm{z})$.

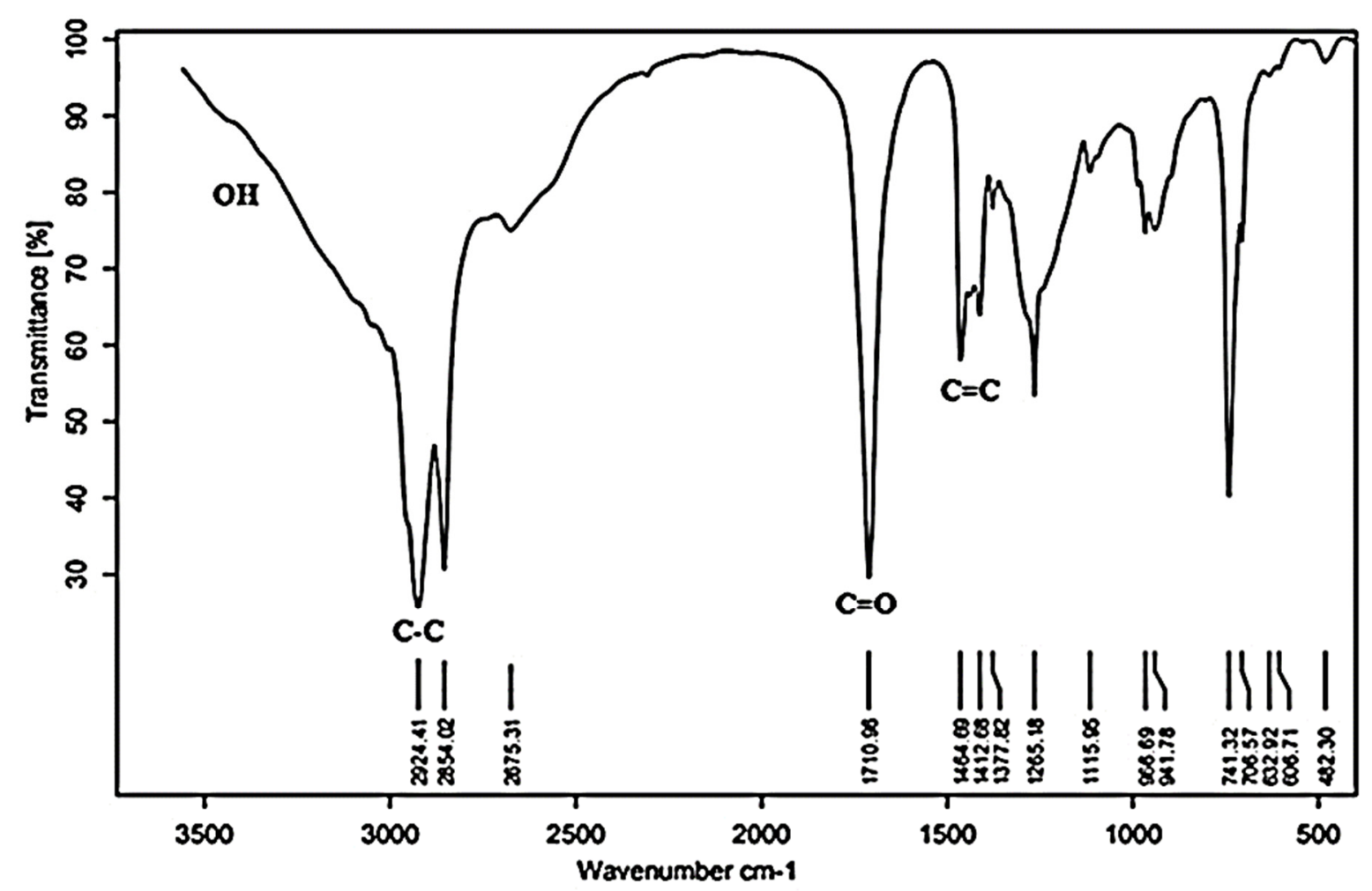

Figure 2. FTIR spectrum of the isolated biosurfactant of Candida sphaerica cultivated in medium supplemented with $9 \%$ vegetable oil refinery residue and $9 \%$ corn steep liquor.

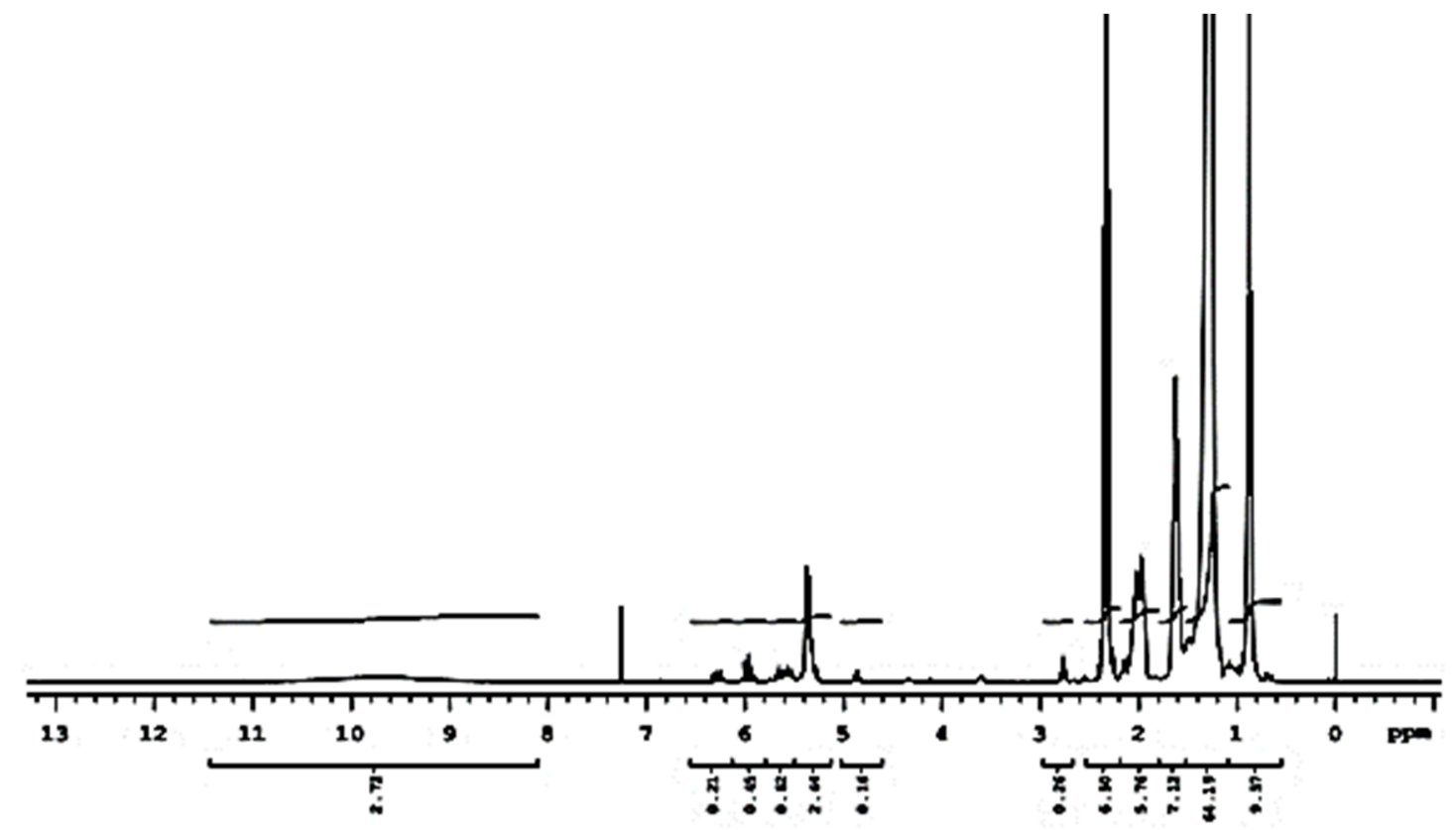

Figure 3. ${ }^{1} \mathrm{H}$ NMR spectrum $\left(\mathrm{CD}_{3} \mathrm{OD}, 300 \mathrm{MHz}\right)$ of the isolated biosurfactant of Candida sphaerica cultivated in medium supplemented with $9 \%$ vegetable oil refinery residue and $9 \%$ corn steep liquor. 

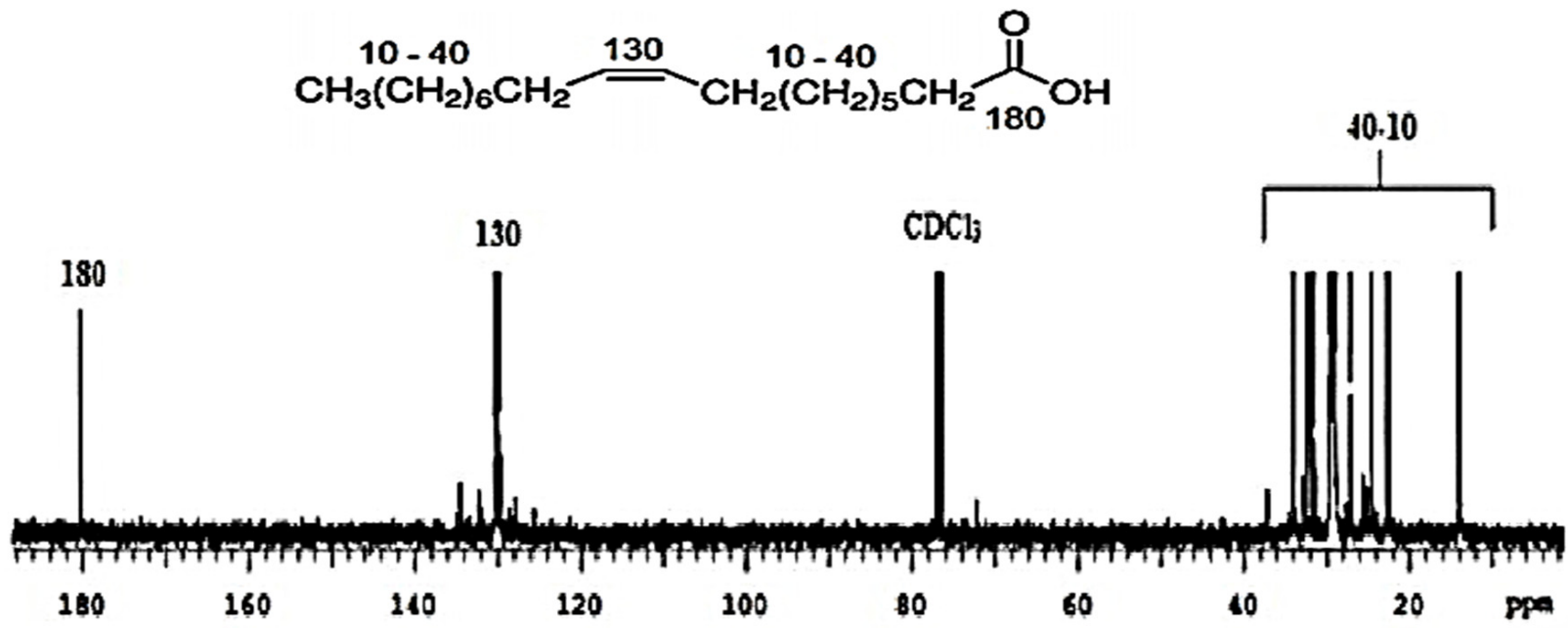

Figure 4. ${ }^{13} \mathrm{C}$ NMR spectrum recorded in $\mathrm{CDCl}_{3}$ of the isolated biosurfactant of Candida sphaerica cultivated in medium supplemented with $9 \%$ vegetable oil refinery residue and $9 \%$ corn steep liquor.

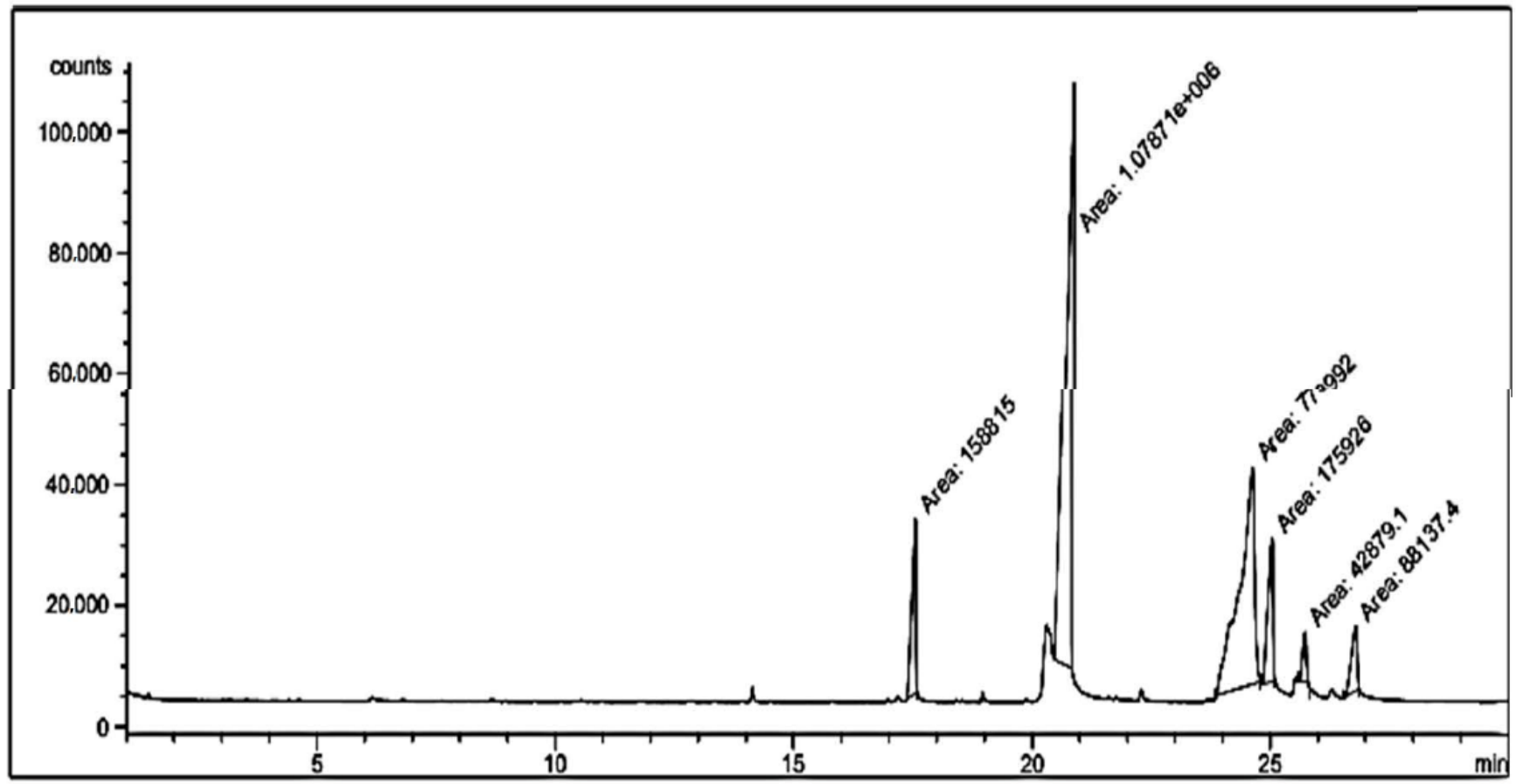

Figure 5. Gas chromatography-mass spectrum of the biosurfactant of Candida sphaerica cultivated in medium supplemented with $9 \%$ vegetable oil refinery residue and $9 \%$ corn steep liquor.

Based on the ${ }^{1} \mathrm{H}$ and C NMR, FTIR, and GC-MS results, we can infer that the biosurfactant produced by $C$. sphaerica may be a glycolipid, given the presence mainly of carboxyl groups attributable to uptaken fatty acids, likely bonded to carbohydrates. These results agree with those reported in previous studies, in which biosurfactants produced by other species belonging to the genus Candida were characterized. For instance, Santos et al. [25] reported the promising production of a biosurfactant by Candida lipolytica cultivated in a medium containing animal fat, and whose characterization suggested its glycolipid nature. Garg et al. [12] reported the production by Candida parapsilosis of a biosurfactant with functional groups similar to those detected in biosurfactants produced by Candida albicans, C. lipolytica, and C. tropicalis MTCC 230. Finally, El-Sheshtawy et al. [11] identified, in a biosurfactant produced by C. albicans, structural details such as hydroxyl and carboxyl 
groups as well as aliphatic carbons, indicating that this compound was a sophorolipid, i.e., a surface-active glycolipid of the disaccharide sophorose.

\subsection{Stability of Formulated Biosurfactant}

Long-term stability is one of the requirements for the development and marketing of a new biotechnological product, whose properties should not change drastically with the variation in $\mathrm{pH}$, temperature, and salinity found in industrial environments [13].

To ensure a stable bioproduct, the crude biosurfactant (cell-free broth) produced by $C$. sphaerica was subjected to different storage conditions $(\mathrm{pH}$, temperature, and the presence of salt), and its surface-active properties (surface tension, emulsification activity, and dispersion capacity) were analyzed over a period of 120 days.

Figure 6 shows the surface tension results of the biosurfactant submitted to different preservation treatments, namely (a) addition of $0.2 \%$ potassium sorbate, (b) fluent steam $+0.2 \%$ potassium sorbate, and (c) fractionated tyndallization, and stored for different periods of time under different $\mathrm{pH}$ values $\left(5.0,7.0\right.$, and 9.0), temperatures $\left(40\right.$ and $\left.50{ }^{\circ} \mathrm{C}\right)$, and concentrations of $\mathrm{NaCl}(1.0,3.0$, and $5.0 \%)$. The surface tension of the formulated biosurfactant remained practically stable in the tested temperature range (Figure 6a-c). The biosurfactant did not show any significant variation in surface tension by changing each of the storage conditions tested, as this property remained around $27.0,28.5$, and $29.0 \mathrm{mN} / \mathrm{m}$ after preserving the biosurfactant with the three methods in the order mentioned above.

(a)

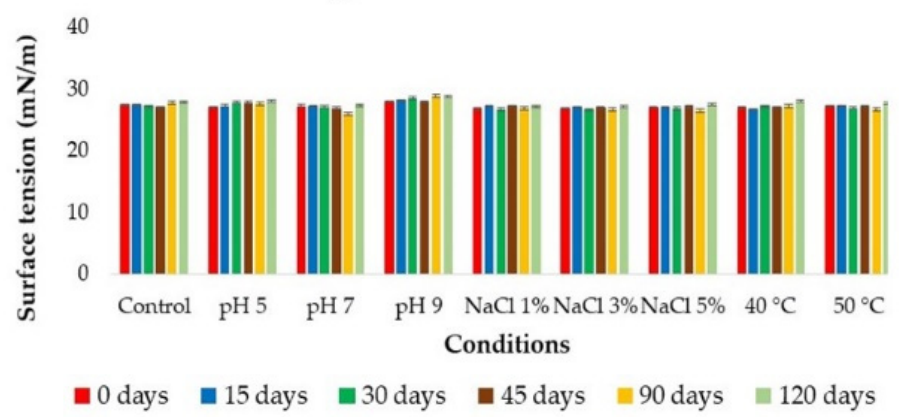

(b)

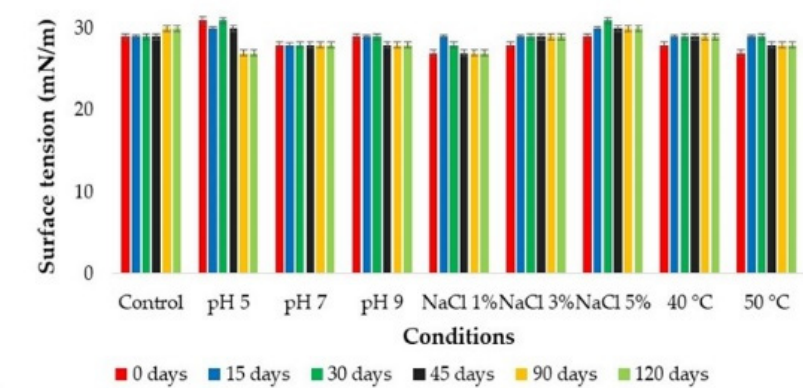

(c)

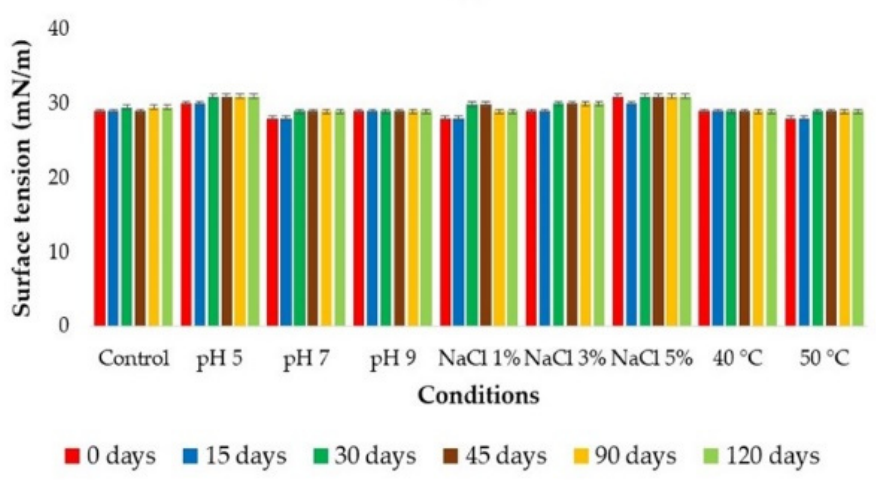

Figure 6. Surface tension results of the biosurfactant produced by Candida sphaerica submitted to different preservation treatments, (a) $0.2 \%$ potassium sorbate, (b) fluent steam $+0.2 \%$ potassium sorbate, (c) fractionated tyndallization, and stored under different conditions over a period of 120 days.

Studies conducted with the biosurfactant produced by Candida bombicola showed qualitatively similar results in terms of stability, since small variations in surface tension were observed when it was preserved with the three different protocols for 120 days, especially using potassium sorbate and fluent steam plus sorbate [18]. Santos et al. [26] also reported satisfactory results for a formulation of $C$. lipolytica biosurfactant, which 
showed small surface tension variations over the same period. However, the results of this study demonstrated that potassium sorbate, a widely used preservative to inhibit the growth of microorganisms, did not cause significant changes in the active-tension capacity of the biomolecule. This suggests the possibility of using such a biosurfactant under environmental conditions of $\mathrm{pH}$, temperature, and salinity economically suitable for the production process.

\subsection{Emulsification Activity with Motor Oil}

The results of Figure 7 shows that the emulsification index of the biosurfactant submitted to the same preservation and storage protocols remained stable under all conditions tested, reaching approximately $100 \%$ emulsification of motor oil throughout 120 days of storage.

(a)

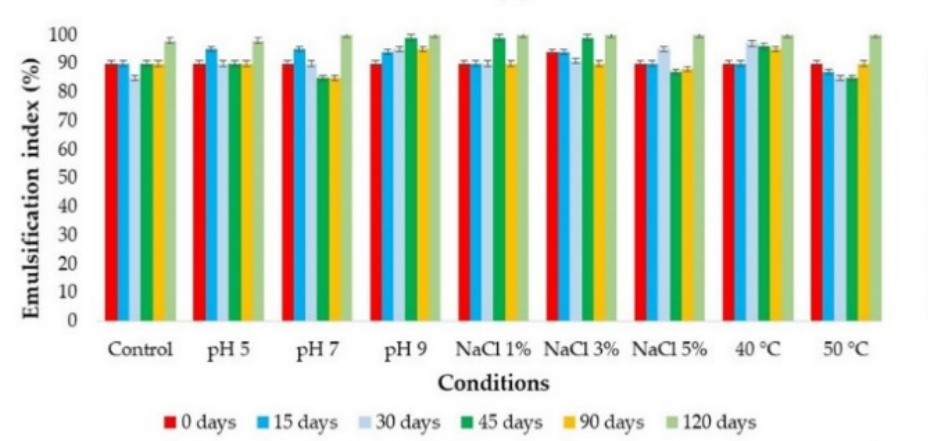

(b)

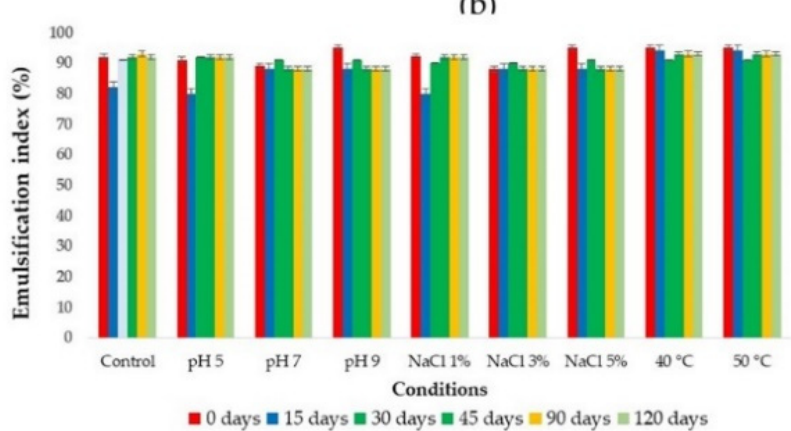

(c)

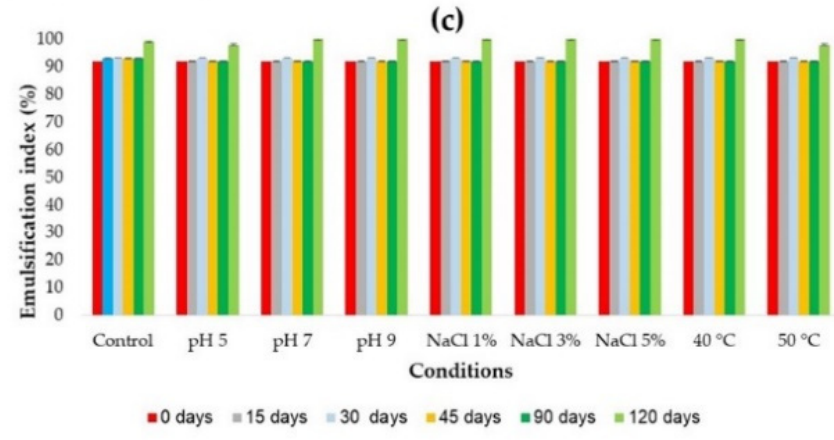

Figure 7. Emulsification index of the biosurfactant produced by Candida sphaerica submitted to different preservation treatments, (a) $0.2 \%$ potassium sorbate, (b) fluent steam $+0.2 \%$ potassium sorbate, (c) fractionated tyndallization, and stored under different conditions over a period of 120 days.

The formulated biosurfactant maintained its stability at different temperatures (40 and $50{ }^{\circ} \mathrm{C}$ ), reaching approximately $100 \%$ emulsification of motor oil over 120 days (Figure $7 \mathrm{a}-\mathrm{c}$ ).

These results, along with those of surface tension, demonstrate the long-term stability of the biosurfactant produced by C. sphaerica.

\subsection{Application of Biosurfactant as Dispersant}

Several processes of the oil industry are offshore operations carried out in the sea, during which a portion of the petroleum handled is accidentally spilled overboard, thus requiring the use of surfactants, as well as other containment measures [27].

Figure 8 shows the motor oil dispersion capacity of the biosurfactant produced by C. sphaerica subjected to the same preservation and storage protocols described above at a biosurfactant-to-oil ratio of 1:2 $(v / v)$. The formulated biosurfactant exhibited the greatest dispersion capacity after 120 days of storage, with the best performance $(90 \%$ dispersion index) achieved using $0.2 \%$ potassium sorbate at 40 or $50{ }^{\circ} \mathrm{C}$, while the use of either fluent steam plus $0.2 \%$ potassium sorbate or fractionated tyndallization was disappointing (only about $5 \%$ dispersion index). 
(a)

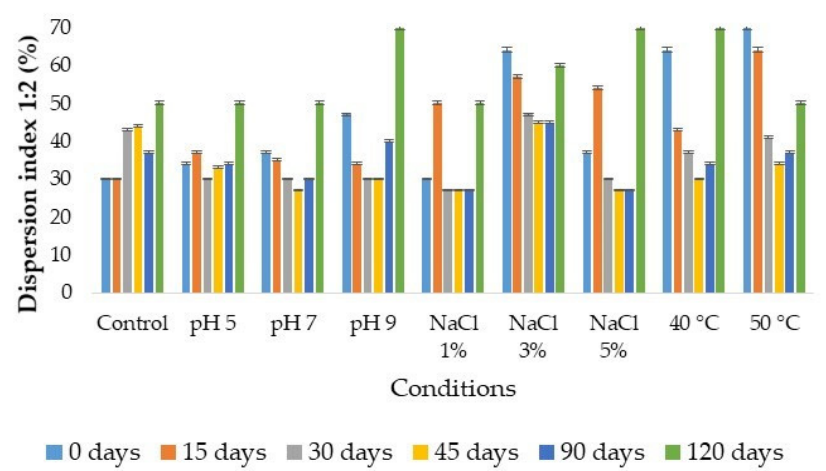

(b)

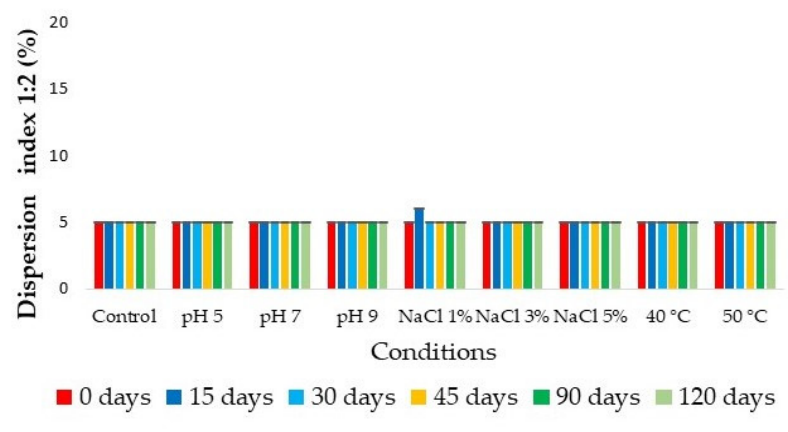

(c)

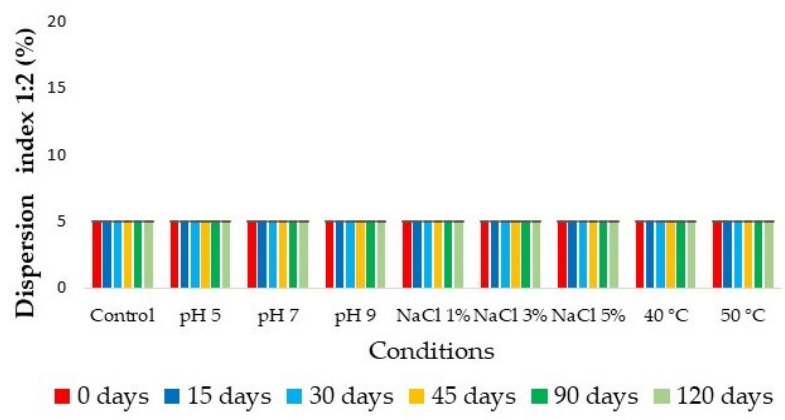

Figure 8. Motor oil dispersion index of the biosurfactant produced by Candida sphaerica, submitted to different preservation treatments, (a) $0.2 \%$ potassium sorbate, (b) fluent steam $+0.2 \%$ potassium sorbate, (c) fractionated tyndallization, and stored under different conditions over a period of 120 days. Biosurfactant-to-oil proportion = 1:2 $(v / v)$.

It is likely that the heat treatment used in the procedures of fractionated tyndallization and fluent steam had a strong impact on some properties of the biosurfactant, such as the dispersion capacity. Moreover, the dispersion capacity may have also been influenced by the interfacial tension together with the shear rate or force; therefore, deeper investigation is required in later studies. On the other hand, other properties such as surface tension and emulsification capacity were more resistant to temperature variation and remained practically stable.

Freitas et al. [18], using the same preservation and storage protocols for a biosurfactant from C. bombicola, found that potassium sorbate addition and fluent vaporization were the most appropriate methods. On the other hand, a biosurfactant produced by Pseudomonas cepacia was shown to be stable after being submitted to fractionated tyndallization and addition of potassium sorbate [13].

In summary, these results taken together suggest that preserving the biosurfactant by adding potassium sorbate would be an efficient formulation procedure for its commercial exploitation as an agent to remove oil spills. The capacity of a biosurfactant to disperse oil is in fact extremely important in environments polluted by hydrocarbons, as this property speeds up its mobilization by breaking it down into droplets, thereby expanding the surface area in contact with oil-degrading microorganisms. Therefore, the use of biosurfactants with good washing and dispersion capacity is an attractive option when an ecosystem is threatened by hydrophobic pollutants. Such natural surfactants have notable economic advantages when used in environmental applications, as they require no expensive steps of isolation and purification. 


\subsection{Cytotoxicity}

Figure 9 shows the results of the MTT assay performed on mouse fibroblasts (L929) to assess the cytotoxicity of the $C$. sphaerica biosurfactant. Cell viability was higher than $90 \%$ at all biosurfactant concentrations tested, which means that it did not exhibit toxicity to the selected cell line, hence confirming its biocompatibility with the requirements of diverse industrial sectors.

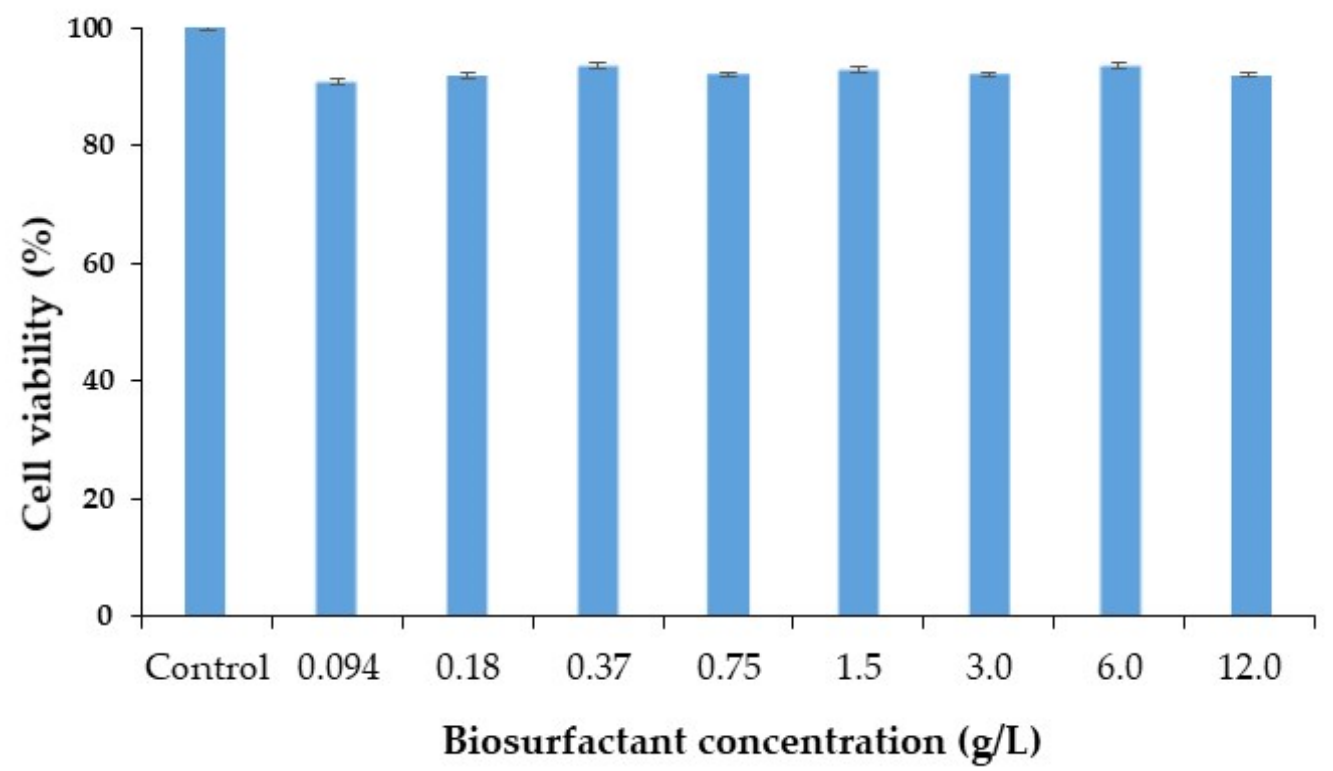

Figure 9. Percentage of mouse fibroblasts (L929) viability assessed with the MTT assay.

A rhamnolipid produced by Pseudomonas aeruginosa showed toxicity at concentrations equal to or greater than $0.20 \mathrm{~g} / \mathrm{L}$ in tests with the HepG2 cell line (human hepatoma) [28], while another one produced by Aspergillus niger showed no cytotoxic activity to mouse fibroblast cells (18.75\% inhibition of growth) [29]. Ribeiro et al. [30] found that biosurfactants obtained from Saccharomyces cerevisiae and Candida utilis did not show cytotoxicity against the non-cancerous L929 and RAW 264.7 cell lines. Finally, Marqués et al. [31] reported lower toxicity of a biosurfactant produced by Rhodococcus sp. 51T7 compared to synthetic counterparts.

\subsection{Static Assay}

Poor availability of hydrocarbons, due to (a) low water-solubility, (b) high fixation to the ground matrix, and (c) poor transfer of adsorbed contaminants from the solid phase to the aqueous one, is one of the factors limiting the bioremediation of polluted soil. Therefore, biosurfactants can be used to microbially enhance their availability [23].

Laboratory studies using sand columns are appropriate for evaluating microbiallyenhanced oil recovery. This is a cheap model in which a battery of columns can be used simultaneously and can simulate oil recovery operations commonly performed in tanks [32].

For this purpose, the crude (cell-free broth) and isolated forms of the biosurfactant produced by C. sphaerica UCP0995 were tested for their ability to remove the oil absorbed to sand in static column tests, while water was used as the control.

Agreeing with reports in the literature [33,34], the removal of motor oil using the C. sphaerica biosurfactant in packed glass columns demonstrated the influence of the biosurfactant concentration, as the removal rate of percolating liquids increased in the following order: distilled water $(7 \%)$, Tween $80(12 \%)$, crude biosurfactant (cell-free broth) $(80 \%)$, biosurfactant at CMC $(67 \%)$, biosurfactant at $\frac{1}{2} \mathrm{CMC}$, and biosurfactant at $2 \times \mathrm{CMC}$ $(70 \%)$. The higher efficiency of the crude biosurfactant in removing engine oil compared to the isolated biosurfactant suggests that it could be used without purification, which would 
be a great economic advantage, considering that the purification processes can represent up to $60 \%$ of the total cost of the biosurfactant [33].

Rufino et al. [23], using packed columns, observed a similar influence of biosurfactant concentration, and reported yields of $7 \%$ for distilled water, $12 \%$ for Tween $80,26 \%$ for biosurfactant crude (cell-free broth), and 33 and $37 \%$ for the isolated biosurfactant from C. lipolytica at CMC and $3 \times \mathrm{CMC}$, respectively. Ashish and Debnath [35] found that the isolated biosurfactant from C. tropicalis allowed a $39.80 \%$ removal yield of hydrocarbons in packed columns. El-Sheshtawy et al. [11] found an 8.6\% removal yield of oil in columns of sand using the isolated biosurfactant from $C$. albicans. Other researchers reported oil recovery yields ranging from 20 to $60 \%$, using biosurfactants produced by different microbial species, such as Bacillus firmus BG4, Bacillus halodurans BG5 [36], Bacillus subtilis [37], and P. aeruginosa [38]. Finally, Batista et al. [33] reported that the crude biosurfactant produced by C. tropicalis removed 78 to $97 \%$ of motor oil absorbed to sand. In another study, the crude biosurfactant produced by Candida guilliermondii grown in industrial waste products removed approximately $90 \%$ of motor oil absorbed to sand [39].

Due to their amphipathic nature, biosurfactants form micellar aggregates with the contaminants, increasing the removal yield. Therefore, the present results indicated that the biosurfactant produced by C. sphaerica UCP0995 has the capacity to reduce the interfacial tension of the oil, thereby facilitating its mobilization.

\subsection{Bioremediation of Petroleum Product Adsorbed on the Sand}

Final tests were also performed to determine the potential of $C$. sphaerica biosurfactant in bioremediation processes, and the results are illustrated in Figure 10 in terms of percentage removal of motor oil adsorbed on the sand by biodegradation.

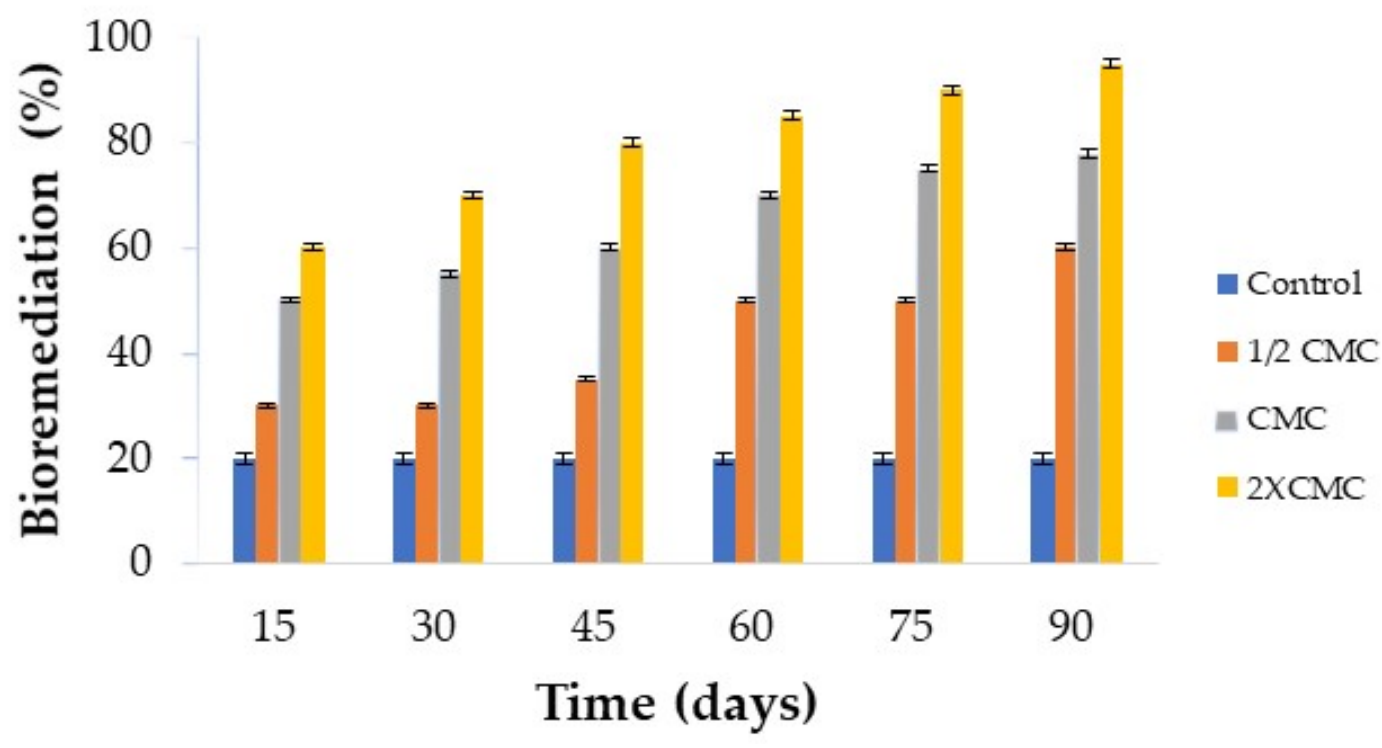

Figure 10. Percentage removal of oil adsorbed to sand by biodegradation using the biosurfactant produced by Candida sphaerica.

The addition of biosurfactant increased the oil removal yield compared to the condition without biosurfactant taken as a control, with the highest removal (95\%) achieved after 90 days using the biosurfactant at a concentration of $2 \times \mathrm{CMC}$. Such a progressive improvement of the removal yield with increasing concentration of the isolated biosurfactant can be ascribed to an increase in oil solubilization in the aqueous phase promoted by the biosurfactant above the CMC.

Two mechanisms are known to control the removal of hydrophobic contaminants from the soil by means of surfactants. The first, called mobilization, occurs below the CMC, in which surfactant monomers increase the contact angle between the soil and hydrophobic contaminant, enabling the separation of the contaminant from the soil particles, and the 
consequent displacement of the oil. The second, known as solubilization, occurs above the $\mathrm{CMC}$, and is the result of contaminant partitioning towards the center of surfactant micelles $[7,40]$. Therefore, the addition of biosurfactants to promote biostimulation has positive effects on the desorption of hydrophobic organic compounds adsorbed on the soil and their solubility, especially when biosurfactants are used at concentrations above the CMC [41].

Lai et al. [42] tested the removal effectiveness of bacterial biosurfactants over a period of seven days, demonstrating that $24 \mathrm{~h}$ were sufficient for the solubilization of hydrocarbons. In another study, the addition of a solution of a C. sphaerica biosurfactant at a concentration of $0.1 \%$ allowed the removal of no less than $65 \%$ of the engine oil adsorbed on the soil, while at the CMC (0.08\%) and a lower concentration $(0.05 \%)$ oil removal was $55 \%$ and approximately $30 \%$, respectively [15]. In a study by Chaprão et al. [40], biosurfactants from C. sphaerica and Bacillus sp. ensured oil removals as high as 70 and $80 \%$, respectively, while an isolated biosurfactant from Candida glabrata allowed an 84\% motor oil removal [43]. Moreover, Santos et al. [25] demonstrated the considerable capacity of a biosurfactant produced by $C$. lipolytica in removing engine oil and petroleum adsorbed on the sand. Using a P. cepacia biosurfactant, Soares da Silva et al. [13] observed removals greater than $70 \%$, with the highest outcome (96\%) obtained when the isolated biosurfactant was used at a concentration of $2 \times \mathrm{CMC}$.

The results of the current study, together with the literature reports on the bioremediation of ground contaminated by petroleum derivatives, confirm the beneficial role of biosurfactants in the biodegradation of hydrocarbons.

\section{Conclusions}

This paper described the production of a low-cost biosurfactant from Candida sphaerica UCP 0995 in a bioreactor according to a central composite rotatable design. The results demonstrated that the use of bioreactors considerably enhanced the yield of the biosurfactant, which increases its chances of industrial application. The formulated biosurfactant maintained its surfactant properties over a long storage time, and the results of motor oil removal tests indicated that it has the capacity to reduce the interfacial tension of the oil, thereby facilitating its mobilization. Structural characterization suggested that the biosurfactant is a glycolipid. The biomolecule had no cytotoxic effect when placed in contact with the L929 cell line, demonstrating that it is harmless to the environment. It also proved effective in removing oil adsorbed on the soil, showing potential in bioremediation applications aimed at recovering environments polluted by oily residues.

Author Contributions: Conceptualization, J.M.d.L. and L.A.S.; methodology, E.M.d.S.S., I.R.A.d.S.L., H.M.M., J.d.S.A. and D.G.d.A.; investigation, E.M.d.S.S., I.R.A.d.S.L., H.M.M., J.d.S.A. and D.G.d.A.; validation, J.M.d.L., J.d.S.A. and R.D.R.; writing—original draft preparation, J.M.d.L., L.A.S. and A.C.; writing-review and editing, J.M.d.L., L.A.S., A.A.C. and A.C.; visualization, J.M.d.L. and R.D.R.; supervision, J.M.d.L. and L.A.S.; project administration, L.A.S.; funding acquisition, L.A.S. and A.C. All authors have read and agreed to the published version of the manuscript.

Funding: This study was funded by the Programa de Pesquisa e Desenvolvimento da Agência Nacional de Energia Elétrica (ANEEL), Centrais Elétricas da Paraíba (EPASA), Centrais Elétricas de Pernambuco S.A. (EPESA), Termocabo S.A., and by Brazilian development agencies Fundação de Apoio à Ciência e Tecnologia do Estado de Pernambuco (FACEPE), Conselho Nacional de Desenvolvimento Científico e Tecnológico (CNPq) and Coordenação de Aperfeiçoamento de Pessoal de Nível Superior (CAPES).

Institutional Review Board Statement: Not applicable.

Informed Consent Statement: Not applicable.

Data Availability Statement: The data presented in this study are available on request from the corresponding author. 
Acknowledgments: The authors are grateful to the Centro de Ciências e Tecnologia da Universidade Católica de Pernambuco (UNICAP) and to the Instituto Avançado de Tecnologia e Inovação (IATI), Brasil.

Conflicts of Interest: The authors declare no conflict of interest.

\section{References}

1. Cardona, D.S.; Debs, K.B.; Lemos, S.G.; Vitale, G.; Nassar, N.N.; Carrilho, E.N.V.M.; Semensatto, D.; Labuto, G. A comparison study of cleanup techniques for oil spill treatment using magnetic nanomaterials. J. Environ. Manag. 2019, 242, 362-371. [CrossRef] [PubMed]

2. Karlapudi, A.P.; Venkateswarulu, T.C.; Tammineedi, J.; Kanumuri, L.; Ravuru, B.K.; Dirisala, V.R.; Kodali, V.P. Role of biosurfactants in bioremediation of oil pollution-a review. Petroleum 2018, 4, 241-249. [CrossRef]

3. Ostendorf, T.A.; Silva, I.A.; Converti, A.; Sarubbo, L.A. Production and formulation of a new low-cost biosurfactant to remediate oil-contaminated seawater. J. Biotechnol. 2019, 295, 71-79. [CrossRef]

4. Almeida, D.G.; da Silva, R.d.C.F.S.; Luna, J.M.; Rufino, R.D.; Santos, V.A.; Sarubbo, L.A. Response surface methodology for optimizing the production of biosurfactant by Candida tropicalis on industrial waste substrates. Front. Microbiol. 2017, 8, 1-13. [CrossRef] [PubMed]

5. Ojuederie, O.B.; Babalola, O.O. Microbial and plant-assisted bioremediation of heavy metal polluted environments: A review. Int J. Environ. Res. Public Health 2017, 14, 1504. [CrossRef]

6. Dell'Anno, F.; Sansone, C.; Ianora, A.; Dell'Anno, A. Biosurfactant-induced remediation of contaminated marine sediments: Current knowledge and future perspectives. Mar. Environ. Res. 2018, 137, 196-205. [CrossRef]

7. Silva, E.J.; Correa, P.F.; Almeida, D.G.; Luna, J.M.; Rufino, R.D.; Sarubbo, L.A. Recovery of contaminated marine environments by biosurfactant-enhanced bioremediation. Colloids Surf. B 2018, 172, 127-135. [CrossRef]

8. Felix, A.K.N.; Martins, J.J.L.; Almeida, J.G.L.; Giro, M.E.A.; Cavalcante, K.F.; Melo, V.M.M.; Pessoa, O.D.L.; Rocha, M.V.P.; Gonçalves, L.R.B.; Aguiar, R.S.S. Purification and characterization of a biosurfactant produced by Bacillus subtilis in cashew apple juice and its application in the remediation of oil-contaminated soil. Colloids Surf. B 2019, 175, 256-263. [CrossRef]

9. Campos, J.M.; Montenegro Stamford, T.L.; Sarubbo, L.A.; de Luna, J.M.; Rufino, R.D.; Banat, I.M. Microbial biosurfactants as additives for food industries. Biotechnol. Prog. 2013, 29, 1097-1108. [CrossRef]

10. Santos, D.K.F.; Brandão, Y.B.; Rufino, R.D.; Luna, J.M.; Salgueiro, A.A.; Santos, V.A.; Sarubbo, L.A. Optimization of cultural conditions for biosurfactant production from Candida lipolytica. Biocatal. Agric. Biotechnol. 2014, 3, 48-57. [CrossRef]

11. El-Sheshtawy, H.S.; Aiad, I.; Osman, M.E.; Abo-ELnasr, A.A.; Kobisy, A.S. Production of biosurfactants by Bacillus licheniformis and Candida albicans for application in microbial enhanced oil recovery. Egypt. J. Pet. 2016, 25, 293-298. [CrossRef]

12. Garg, M.; Priyanka; Chatterjee, M. Isolation, characterization and antibacterial effect of biosurfactant from Candida parapsilosis. Biotechnol. Rep. 2018, 18, e00251. [CrossRef] [PubMed]

13. Soares da Silva, R.D.C.F.; Almeida, D.G.; Brasileiro, P.P.F.; Rufino, R.D.; de Luna, J.M.; Sarubbo, L.A. Production, formulation and cost estimation of a commercial biosurfactant. Biodegradation 2018, 30, 191-201. [CrossRef] [PubMed]

14. Marchant, R.; Banat, I.M. Microbial biosurfactants: Challenges and opportunities for future exploitation. Trends Biotechnol. 2012, 30, 558-565. [CrossRef]

15. Sobrinho, H.B.S.; Rufino, R.D.; Luna, J.M.; Salgueiro, A.A.; Campos-Takaki, G.M.; Leite, L.F.C.; Sarubbo, L.A. Utilization of two agroindustrial by-products for the production of a surfactant by Candida sphaerica UCP0995. Process Biochem. 2008, 43, 912-917. [CrossRef]

16. Luna, J.M.; Rufino, R.D.; Sarubbo, L.A.; Campos-Takaki, G.M. Characterization, surface properties and biological activity of a biosurfactant produced from industrial waste by Candida sphaerica UCP0995 for application in the petroleum industry. Colloids Surf. B 2013, 102, 202-209. [CrossRef]

17. Silva, I.A.; Veras, B.O.; Ribeiro, B.G.; Aguiar, J.S.; Campos Guerra, J.M.; Luna, J.M.; Sarubbo, L.A. Production of cupcake-like dessert containing microbial biosurfactant as emulsifier. Peer J. 2020, 8, 9064. [CrossRef]

18. Freitas, B.G.; Brito, J.G.M.; Brasileiro, P.P.F.; Rufino, R.D.; Luna, J.M.; Santos, V.A.; Sarubbo, L.A. Formulation of a commercial biosurfactant for application as a dispersant of petroleum and by-products spilled in oceans. Front. Microbiol. 2016, 7, 1646. [CrossRef]

19. Cooper, D.G.; Goldenberg, B.G. Surface-active agents from two Bacillus species. Appl. Environ. Microbiol. 1987, 53, 224-229. [CrossRef]

20. Alley, M.C.; Scudiero, D.A.; Monks, P.A.; Hursey, M.L.; Czerwinski, M.J.; Fine, D.L.; Abbott, B.J.; Mayo, J.G.; Shoemaker, R.H.B.; Boyd, M.R. Feasibility of drug screening with panels of human tumor cell lines using a microculture tetrazolium assay. Cancer Res. 1998, 48, 589-601.

21. Mosmann, T. Rapid colorimetric assay for cellular growth and survival: Application to proliferation and cytotoxicity assays. J. Immunol. Methods 1983, 65, 55-63. [CrossRef]

22. Joshi, S.; Yadav, S.; Desai, A.J. Application of response-surface methodology to evaluate the optimum medium components for the enhanced production of lichenysin by Bacillus licheniformis R2. Biochem. Eng. J. 2008, 41, 122-127. [CrossRef]

23. Rufino, R.D.; Luna, J.M.; Marinho, P.H.C.; Farias, C.B.B.; Ferreira, S.R.M.; Sarubbo, L.A. Removal of petroleum derivative adsorbed to soil by biosurfactant Rufisan produced by Candida lipolytica. J. Pet. Sci. Eng. 2013, 109, 117-122. [CrossRef] 
24. Chen, Q.; Bao, M.; Fan, X.; Liang, S.; Sun, P. Rhamnolipids enhance marine oil spill bioremediation in laboratory system. Mar. Pollut. Bull. 2013, 71, 269-275. [CrossRef] [PubMed]

25. Santos, D.K.F.; Meira, H.M.; Rufino, R.D.; Luna, J.M.; Sarubbo, L.A. Biosurfactant production from Candida lipolytica in bioreactor and evaluation of its toxicity for application as a bioremediation agent. Process Biochem. 2017, 54, 20-27. [CrossRef]

26. Santos, D.K.F.; Resende, A.H.M.; Almeida, D.G.; Silva, R.C.F.S.; Rufino, R.D.; Luna, J.M.; Banat, I.M.; Sarubbo, L.A. Candida lipolytica UCP0988 biosurfactant: Potential as a bioremediation agent and in formulating a commercial related product. Front. Microbiol. 2017, 8, 767. [CrossRef]

27. Almeida, D.G.; Soares da Silva, R.d.C.F.; Luna, J.M.; Rufino, R.D.; Santos, V.A.; Banat, I.M.; Sarubbo, L.A. Biosurfactants: Promising molecules for petroleum biotechnology advances. Front. Microbiol. 2016, 7, 1718. [CrossRef]

28. Fernandes, T.C.C. Investigação dos Efeitos Tóxicos do Biossurfactante Ramnolipídio e suas Implicações Quando Usado na Biorremediação de Águas Contaminadas por Petróleo. Ph.D. Thesis, Universidade Estadual Paulista, Rio Claro, SP, Brazil, 2011.

29. Silva, G.K.B. Isolamento, identificação, Caracterização e Potencial Biotecnológico na Produção de Biossurfactante por Aspergillus niger UCP/WFCC 1355 Isolado de Solo da Caatinga-PE, Brasil. Ph.D. Thesis, Universidade Federal de Pernambuco, Recife, PE, Brazil, 2015.

30. Ribeiro, B.G.; Guerra Campos, J.M.; Sarubbo, L.A. Potential food application of a biosurfactant produced by Saccharomyces cerevisiae URM 6670. Front. Bioeng. Biotechnol. 2020, 8, 434. [CrossRef]

31. Marqués, A.M.; Pinazo, A.; Farfan, M.; Aranda, F.J.; Teruel, J.A.; Ortiz, A.; Manresa, A.; Espuny, M.J. The physicochemical properties and chemical composition of trehalose lipids produced by Rhodococcus erythropolis 51T7. Chem. Phys. Lipids 2009, 158, 110-117. [CrossRef]

32. Sarubbo, L.A.; Rocha, R.B.; Luna, J.M.; Rufino, R.D.; Santos, V.A.; Banat, I.M. Some aspects of heavy metals contamination remediation and role of biosurfactants. Chem. Ecol. 2015, 31, 707-723. [CrossRef]

33. Batista, R.M.; Rufino, R.D.; Luna, J.M.; de Souza, J.E.G.; Sarubbo, L.A. Effect of medium components on the production of a biosurfactant from Candida tropicalis applied to the removal of hydrophobic contaminants in soil. Water Environ. Res. 2010, 82, 418-425. [CrossRef] [PubMed]

34. Urum, K.; Pekdemir, T.; Gopur, M. Optimum conditions for washing of crude oil-contaminated soil with biosurfactant solutions. Process Saf. Environ. Prot. Trans. Inst. Chem. Eng. Part B 2003, 81, 203-209. [CrossRef]

35. Ashish; Debnath, M. Application of biosurfactant produced by an adaptive strain of $C$. tropicalis MTCC230 in microbial enhanced oil recovery (MEOR) and removal of motor oil from contaminated sand and water. J. Pet. Sci. Eng. 2018, 170, 40-48. [CrossRef]

36. Shibulal, B.; Al-Bahry, S.; Al-Wahaibi, Y.; Elshafie, A.; Al-Bemani, A.; Joshi, S. Microbial-enhanced heavy oil recovery under laboratory conditions by Bacillus firmus BG4 and Bacillus halodurans BG5 isolated from heavy oil fields. Colloids Interfaces 2018, 2, 1. [CrossRef]

37. Gudiña, E.J.; Pereira, J.F.B.; Costa, R.; Coutinho, J.A.P.; Teixeira, J.A.; Rodrigues, L.R. Biosurfactant-producing and oil-degrading Bacillus subtilis strains enhance oil recovery in laboratory sand-pack columns. J. Hazard. Mater. 2013, 261, 106-113. [CrossRef]

38. Cameotra, S.S.; Makkar, R. Synthesis of biosurfactants in extreme conditions. Appl. Microbiol. Biotechnol. 1998, 50, 520-529. [CrossRef]

39. Coimbra, C.D.; Rufino, R.D.; Luna, J.M.; Sarubbo, L.A. Studies of the cell surface properties of Candida species and relation to the production of biosurfactants for environmental applications. Curr. Microbiol. 2009, 58, 245-251. [CrossRef]

40. Chaprão, M.J.; Ferreira, I.N.S.; Correa, P.F.; Rufino, R.D.; Luna, J.M.; Silva, E.J.; Sarubbo, L.A. Application of bacterial and yeast biosurfactants for enhanced removal and biodegradation of motor oil from contaminated sand. Electron. J. Biotechnol. 2015, 18, 471-479. [CrossRef]

41. Nitschke, M.; Pastore, G.M. Biossurfactantes: Propriedades e aplicações. Química Nova 2002, 25, 772-776. [CrossRef]

42. Lai, C.C.; Huang, Y.C.; Wei, Y.H.; Chang, J.S. Biosurfactant-enhanced removal of total petroleum hydrocarbons from contaminated soil. J. Hazard. Mater. 2009, 167, 609-614. [CrossRef]

43. Luna, J.M.; Sarubbo, L.A.; Campos-Takaki, G.M. A new biosurfactant produced by Candida glabrata UCP 1002: Characteristics of stability and application in oil recovery. Braz. Arch. Biol. Technol. 2009, 52, 785-793. [CrossRef] 